\title{
A ECONOMIA POLÍTICA INTERNACIONAL E O PETRÓLEO NA NIGÉRIA
}

\section{Guilherme Ziebell de Oliveira EdUARDo ERNESTO FILIPPI}

\begin{abstract}
Resumo: A Nigéria, ao longo da década de 1970, atingiu grande autonomia e teve um papel destacado na sua região e no continente africano. Na década seguinte, o país se alinha aos interesses das potências Ocidentais e perde espaço no cenário mundial. Este trabalho analisa, à luz da economia política internacional, a relação entre o petróleo e a política externa nigeriana.
\end{abstract}

Palavras-chave: Petróleo, Política Externa, Economia Política Internacional, Nigéria,

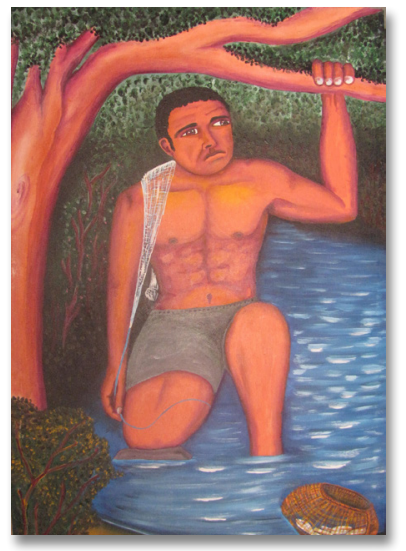

\section{GuILHERME ZiEBELL DE \\ Oliveira}

Doutorando do Programa de Pós-Graduação em

Ciência Política da Universidade Federal do Rio Grande do Sul (PPGPOL - UFRGS).

\section{EdUARDo ERNESTo FiLIPPI}

Professor do

Departamento

de Economia da

Universidade Federal

do Rio Grande do Sul

(UFRGS). Doutor em

Economia Política pela

Université de Versailles.

\section{THE INTERNATIONAL POLITICAL ECONOMY AND OIL IN NIGERIA}

\begin{abstract}
Nigeria, throughout the 1970s, reached considerable autonomy and assumed a leading role in both its region and in the African continent. In the next decade, the country became aligned with the interests of the Western powers and lost ground in the world scene. This work analyzes the relationship between oil and Nigerian foreign policy from an international political economy approach.
\end{abstract}

Keywords: Oil, Foreign Policy, International Political Economy, Nigeria. 


\section{INTRODUÇÃO}

A Nigéria se tornou independente em outubro de 1960. Durante os primeiros anos de independência, o país, que tinha como base de suas exportações produtos agrícolas, adotou uma política externa "tímida", sensivelmente conservadora e ligada ao Reino Unido, sua antiga metrópole. A produção de petróleo, iniciada ainda antes da independência, em 1958, se mostrou um fator de importância menor para a economia nigeriana até o início da década de 1970, quando foi encerrada a guerra civil que atingiu o país a partir de 1967. Desde então, a Nigéria passou por uma rápida expansão de sua produção de petróleo, tornando-se um dos grandes produtores mundiais da commodity.

Em 1971, o país passou a integrar a Organização dos Países Exportadores de Petróleo (OPEP), tendo papel ativo no boicote realizado por essa entidade em 1973, que foi responsável pelo importante aumento no preço internacional do produto. Dessa forma, ao longo da década de 1970, a Nigéria, beneficiada pelo aumento de sua arrecadação, possibilitada pela grande produção e pelos altos preços do petróleo, viveu o auge de sua política externa. Ao longo desse período, o país logrou estabelecer-se como uma das potências africanas e na vanguarda na luta anticolonialista no continente, além de ter adotado uma postura bastante autônoma na elaboração e execução de sua política internacional. A partir do início da década de 1980, frente à diminuição dos preços do petróleo e, consequentemente, da arrecadação nacional, a Nigéria perdeu grande parte dessa autonomia, sendo a década marcada não só pela estagnação econômica do país, mas também pela sua relativa perda de importância no cenário internacional.

Nesse contexto, esse trabalho busca analisar, através da perspectiva da Economia Política Internacional (EPI), a interligação existente entre os preços internacionais (e os choques) do petróleo e a autonomia da política externa nigeriana. Para tanto, primeiramente será feita uma breve revisão acerca da EPI e de seu surgimento como campo de estudos e, em seguida, uma análise da política externa nigeriana desde sua independência, em 1960, até o início da década de 1990, de forma a se compreender a relação existente entre esta e os preços internacionais do petróleo. 
Busca-se demonstrar, assim, que os períodos em que a Nigéria teve uma política externa mais destacada e assertiva (sobretudo a década de 1970) foram aqueles em que os preços internacionais do petróleo estavam elevados e aliados a uma grande produção, assegurando um significativo aporte financeiro para o país e, consequentemente, criando uma poderosa ferramenta de condução de política externa.

Cabe ressaltar que a Nigéria tem sido, historicamente, uma das principais potencias africanas. Além disso, destaca-se que, recentemente, o país ultrapassou a África do Sul como maior economia do continente (OHUOCHA, 2014). A Nigéria, entretanto, se mostra pouco conhecida na academia brasileira - ainda que, desde seu início em 1960, as relações bilaterais entre os dois países tenham sido frutíferas (MACHADO, 2013). O esforço deste trabalho é, nesse sentido, contribuir para a formação de conhecimento sobre um dos principais atores do continente africano, espaço que crescentemente tem sido central nas dinâmicas contemporâneas das relações internacionais (VISENTINI, 2013).

\section{ECONOMIA POLÍTICA INTERNACIONAL: UMA BREVE REVISÃO}

A Economia Política Internacional (EPI), como campo de estudos, surgiu nos primeiros anos da década de 1970 e dois eventos foram bastante significativos para seu desenvolvimento (VESETH, 2001; RAVENHILL, 2008). O primeiro foi o declínio do sistema de Bretton Woods. Após o longo período de estabilidade que se seguiu à Segunda Guerra Mundial, o final da década de 1960 foi marcado por um contexto de crescente instabilidade econômica nos EUA, por conta da pressão exercida em sua economia interna pela equiparação do dólar com o ouro. Assim, em 1971, Nixon desvalorizou unilateralmente o dólar e acabou com a conversibilidade direta entre a moeda e o ouro. Com isso, teve fim o sistema de taxas de câmbio fixas, que era um dos pilares do sistema financeiro de Bretton Woods, e iniciou-se uma nova fase de instabilidade na economia global (RAVENHILL, 2008). 
O segundo evento foi o primeiro choque internacional do petróleo, ocorrido em 1973, com o embargo realizado pelos países membros da OPEP, em protesto contra o apoio estadunidense a Israel na guerra árabe-israelense, que elevou significativamente o preço do barril de petróleo, causando grande impacto na economia mundial. Michael Veseth (2008) destaca quatro dimensões inerentes à EPI evidenciadas com o embargo da OPEP. Primeiramente, ele teria demonstrado a efetividade e o poder das ferramentas econômicas nas relações internacionais. Em segundo lugar, teria deixado claro que as disputas políticas e econômicas entre o Norte e o Sul não poderiam mais ser ignoradas, sendo por vezes muito mais importantes que as disputas Leste-Oeste. Em terceiro lugar, teria deixado clara a complexa interdependência existente entre as questões políticas e econômicas (tanto domésticas, quanto internacionais). Por fim, de acordo com o autor, a mudança nos fluxos de pagamentos estimulada pelo embargo teria sido o início de um movimento em direção a um sistema financeiro global e à globalização econômica generalizada (VESETH, 2001). Além dos preços do petróleo, diversas outras commodities sofreram um aumento de preços no início da década de 1970, levando os países produtores a acreditar que seria possível, através do "poder das commodities", promover uma reestruturação dos regimes econômicos internacionais, criando uma Nova Ordem Econômica Internacional (RAVENHILL, 2008).

Como campo de estudos, a EPI foca na interação entre a política e a economia internacional, bem como na influência gerada e recebida mutuamente por elas (VESETH, 2001). Assim, Ravenhill (2008) destaca a importância do poder político para a EPI, compreendido como a capacidade de um ator mudar o comportamento de outro, ou também como a capacidade de um ator estabelecer e promover agendas específicas, criando regras e estruturas nas relações econômicas internacionais de forma a beneficiar determinados atores e/ou prejudicar outros (RAVENHILL, 2008).

De acordo com Veseth (2001), apesar de ao longo das décadas de 1970 e 1980 o estudo da EPI ter tomado diversos rumos, a agenda foi marcada por seis questões principais: comércio internacional, finanças internacionais, relações Norte-Sul, corporações 
multinacionais, hegemonia mundial e, mais recentemente, globalização. Dentre estas questões, o comércio internacional é a que se mostra mais pertinente para este trabalho (ainda que as relações Norte-Sul, de certa forma, também sejam importantes).

A troca de bens, serviços e recursos entre países gera diversas questões políticas de interesse nacional, tanto em termos econômicos, quanto em termos de segurança. Assim, não apenas as importações e exportações podem ser usadas como uma ferramenta de política externa, mas também a negação destas, consubstanciada nos embargos econômicos. Nesse sentido, parte significativa da preocupação da EPI com o comércio internacional tem sido direcionada para agregar preocupações com segurança econômica e o uso da economia como uma ferramenta de política externa no estudo das relações internacionais, além de agregar fatores políticos às análises de economia internacional (VESETH, 2001).

\section{A POLÍTICA EXTERNA NIGERIANA DESDE O PROCESSO DE INDEPENDÊNCIA}

Logo que a Nigéria se tornou independente, em outubro de 1960, o primeiro-ministro nigeriano, Abubakar Tafawa Balewa, em um pronunciamento ao parlamento, estabeleceu os princípios que norteariam a política externa do país. Ele afirmou que ela seria conduzida de forma independente - baseada nos interesses nacionais - e consistente com os princípios morais e democráticos sobre os quais a Constituição do país estava assentada. Além disso, ela teria como objetivos a defesa da soberania, integridade e independência nacionais nigerianas; a criação de condições econômicas, políticas, sociais e culturais que assegurassem a independência da Nigéria e de outros países africanos; a promoção dos direitos dos povos negros e de todos os outros sob jugo colonial; a promoção da unidade africana; a promoção da paz mundial, estruturada sob a liberdade, o respeito e a igualdade mútua entre todos os povos do mundo; o respeito pela integridade territorial de todas as nações; e o não-alinhamento em relação às disputas entre o Leste e o Oeste, com liberdade de associação e de ação no sistema internacional (GAMBARI, 2008). 
Contudo, a política externa nigeriana ao longo da Primeira República (1960-1966) foi marcada por uma atuação tímida e vacilante, sendo conduzida por um governo que refletia a desunião do país (GAMBARI, 2008), com poder central enfraquecido e governos regionais fortes, que tinham autonomia para elaborar suas próprias políticas externas. As regiões, além disso, mantinham delegações separadas em Londres, o que gerava entraves para a articulação da política externa (WRIGHT; OKOLO, 1999). Mesmo perante a defesa formal do não-alinhamento, ou de um "neutralismo positivo", a política externa da Nigéria nesse período estruturou-se de forma conservadora e pró-Ocidental, fortemente ligada à antiga metrópole, que era a origem de grande parte de suas importações e o destino de grande parte de suas exportações (AKINTERINWA, 2001), e afastada do radicalismo do ganês Kwame Nkrumah (WRIGHT; OKOLO, 1999).

Todavia, em janeiro de 1961, o primeiro-ministro Balewa rompeu as relações diplomáticas com a França, como forma de protesto contra os testes nucleares franceses no Saara (ADEBAJO, 2008). Em resposta, a França buscou dificultar, entre 1963 e 1966, as negociações nigerianas de um acordo de comércio com a Comunidade Econômica Europeia (CEE). As relações entre os dois países foram retomadas em 1966 e a Nigéria, após ter negociado e assinado o acordo com a CEE, não o ratificou (ADEBAJO, 2008). Em relação aos assuntos africanos, a Nigéria adotou um posicionamento pró-descolonização, ainda que de forma bastante conservadora, defendendo que as independências acontecessem de forma negociada (FALOLA; HEATON, 2008)

Ao final da guerra civil que atingiu o país entre 1967 e 1970, o governo federal empreendeu uma rápida expansão do setor petrolífero no Delta do Níger, dando início ao boom do petróleo na década de 1970. A produção, que em 1958 era de cerca de 5.100 bpd (barris de petróleo por dia) e em 1966, imediatamente antes da guerra, já era de 417.000 bpd, passou para 1,1 milhões de bpd em 1970. Dois anos mais tarde, chegou a 1,7 milhões de bpd e, em 1974, atingiu 2,3 milhões de bpd (FALOLA; HEATON, 2008). Rapidamente, a Nigéria assumiu o posto de maior produtor de 
petróleo do continente africano, ocupado pela Líbia desde 1964 (FRYNAS; PAULO, 2007).

Em 1971, foi criada pelo governo a Nigerian National Oil Company (NNOC), que seria responsável por regular o setor petrolífero no país. Além disso, a Nigéria passou a integrar a OPEP, sendo seu décimo-primeiro membro. Em 1973, a organização impôs um embargo aos países ocidentais, devido ao seu apoio a Israel na Guerra do Yom Kippur, em outubro do mesmo ano. Com o embargo, os preços do petróleo aumentaram significativamente, ${ }^{1}$ fazendo crescer também a importância da receita oriunda do petróleo para o governo nigeriano, que diminuiu, ou mesmo extinguiu outras formas de arrecadação, como impostos e tarifas alfandegárias (FALOLA; HEATON, 2008).

Com o progressivo aumento da demanda e os altos preços alcançados, a produção de petróleo passou a ter uma participação cada vez maior na economia nigeriana. Enquanto em 1960 a commodity representava menos de 3\% das exportações nigerianas, em 1971 já era responsável por mais de 73\% (S.I., 2012). Ao mesmo tempo, enquanto entre 1971 e 1972 o petróleo era responsável por cerca de 50\% da arrecadação do governo nigeriano, entre 1975 e 1976 esse percentual já havia subido para 87\%, com o produto representando 93\% das exportações do país. A arrecadação do governo, que em 1970 era de cerca de US\$ 758 milhões, passou para US\$2,17 bilhões em 1973 e US\$ 5,8 bilhões em 1975 (FRANCIS, 2006), tendo o PIB atingido, em 1974, a marca de US\$ 19,4 bilhões, maior do que o PIB de todos os vizinhos combinados (ADEBAJO, 2008). Ademais, ao longo da década de 1970, a produção agrícola, base da economia e das exportações nigerianas por muitos anos, teve crescimento negativo (NUGENT, 2004), com o país se tornando cada vez mais dependente das importações de alimentos (FALOLA; HEATON, 2008), o que, para alguns autores, era uma clara demonstração de que o país vivenciava a Doença Holandesa (Dutch Disease) (AZUBUIKE, 2009).

1 O barril do petróleo passou de US\$3,29, em 1973 (o equivalente a US\$ 17 em 2011), para US\$11,58 em 1974 (o equivalente a US\$ 53,94 em 2011), um aumento de mais de 250\% (BP, 2013). 
O enorme influxo de capitais levou a uma expansão nos gastos do Estado, com uma ampliação do serviço público e amplo investimento em grandes projetos de infraestrutura, como a reconstrução de estradas e aeroportos que haviam sido destruídos durante a guerra. Além disso, foram construídas escolas e quartéis, e foi realizado um aumento na alocação de verba para os militares (FALOLA; HEATON, 2008).

A economia florescente desse período, baseada nas exportações de petróleo, permitiu à Nigéria alcançar proeminência internacional e também buscar políticas vigorosas tanto para a África Ocidental, quanto para o continente como um todo. Desde o início da década de 1970, a Nigéria, que se via crescentemente ameaçada pela influência francesa no Oeste africano, sobretudo após a Guerra de Biafra, ${ }^{2}$ intensificou o seu projeto de criação de uma comunidade econômica na região, como forma de afastar essa influência e consolidar sua liderança regional. Assim, ao longo da primeira metade da década, o governante nigeriano, General Yakubu Gowon, realizou uma série de visitas aos países da região, em uma tentativa de promover o projeto. Foram assinados acordos bilaterais de cooperação econômica com diversos países da região, além do estabelecimento de diversos projetos de investimento nigeriano nos Estados vizinhos.

Ainda assim, a Nigéria conseguiu encontrar apoio ao seu projeto apenas nos países anglófonos da região, além de Benim e Togo, com os quais foi estabelecida uma comunidade embrionária, a Comunidade Econômica da África Ocidental (WAEC, em inglês). Diante de tal contexto, uma comissão ministerial conjunta entre Togo e Nigéria realizou, em agosto de 1973, um tour por todos os países do Oeste africano (exceto Guiné-Bissau), no qual apresentou a todos os líderes uma proposta de união nos moldes da WAEC. A proposta englobava todas as vantagens da Communauté Economique de l'Afrique de l'Ouest (CEAO), a comunidade que

2 Durante a Guerra de Biafra (ou Guerra Civil nigeriana), ainda que não tenha reconhecido oficialmente o governo de Biafra, o governo francês apoiou, informalmente, a região secessionista, seja diretamente, seja através de suas ex-colônias, muitas das quais reconheceram formalmente a independência de Biafra (OLIVEIRA, 2012). 
estava em processo de formação, fomentado pela França, e que abarcava apenas os países francófonos do Oeste africano, além dos mercados e recursos dos países anglófonos. Além disso, deixava claro que se eventuais perdas de subvenções da CEE acontecessem (um receio recorrente entre os Estados francófonos da região), essas seriam certamente compensadas com capital e investimento externo nigeriano (OLIVEIRA, 2012).

Em dezembro do mesmo ano, uma reunião foi realizada em Lomé, contando com a participação de catorze Estados do Oeste africano, para a discussão da proposta de integração e para o estabelecimento de outros encontros, com o objetivo de elaborar um projeto de tratado. A Nigéria assumiu um importante papel nessas negociações. A pujante economia nigeriana, apoiada essencialmente nos imensos lucros do petróleo, contribuiu para que houvesse uma mudança na percepção do poder nigeriano por parte dos outros Estados do Oeste africano, o que se mostrou decisivo na sua adesão aos acordos que implementaram a Comunidade Econômica dos Estados da África Ocidental (ECOWAS, em inglês) efetivamente (FRANCIS, 2006). Após a realização de diversos encontros para a elaboração do tratado de criação da comunidade, este foi assinado em maio de 1975, criando-a oficialmente (ABEGURIN, 2003).

Murtala Mohammed chegou ao poder em 1975, e deu início à terceira fase da política externa nigeriana, tendo sucesso em redirecioná-la para uma postura de não-alinhamento mais genuína. Logo no início de seu governo, ele reconheceu o Movimento Popular de Libertação de Angola (MPLA) como o único representante legítimo do povo angolano, e teve papel fundamental no direcionamento da opinião da Organização da Unidade Africana (OUA) em favor do reconhecimento do MPLA (NAFZIGER, 1992; GAMBARI, 2008). Entre 1975 e 1976, a Nigéria se tornou a liderança africana nas lutas anti-apartheid e pela descolonização, fornecendo apoio a movimentos de libertação através do comitê de libertação da OUA (WILSON III, 1973; ADEBAJO, 2008). Assim, Murtala Mohammed ampliou o apoio diplomático, financeiro e material aos movimentos de libertação da África Austral, o que resultou no convite para que a Nigéria integrasse os encontros 
dos "Estados da Linha de Frente" (Botsuana, Zâmbia e Tanzânia - e, posteriormente, também Angola e Moçambique) (GAMBARI, 2008).

Em fevereiro de 1976, contudo, Murtala Mohammed foi assassinado em uma tentativa frustrada de golpe. O segundo homem no comando, Tenente General Olusegun Obasanjo, então assumiu o poder. Em grande medida, Obasanjo se mostrou bastante alinhado com o governo anterior, com períodos de diferença bastante pontuais, associados, sobretudo, a diminuições no preço internacional do petróleo. Nesse sentido, a Nigéria foi um dos articuladores do boicote aos Jogos Olímpicos de 1976 e aos jogos da Commonwealth de 1978, ambos em protesto contra a participação da Nova Zelândia, que mantinha uma aproximação esportiva com a África do Sul apartheidista (WRIGHT; OKOLO, 1999). Além disso, durante o governo Obasanjo, a Nigéria intensificou seus esforços de mediação na guerra entre Somália e Etiópia (1977-1978), no conflito entre Uganda e Tanzânia (1978-1979) e na disputa do Saara Ocidental (1979), o que levou a um reconhecimento, por parte do Ocidente, da crescente importância política, diplomática e econômica nigeriana no continente africano (GAMBARI, 2008).

Em 1978, os preços do petróleo sofreram uma pequena queda, ${ }^{3}$ o que implicou em uma redução na produção nigeriana (de 2,1 para 1,9 milhões de barris por dia) e, consequentemente, em um crescimento do déficit na balança de pagamentos do país. A resposta do governo Obasanjo veio sob a forma de medidas de austeridade, com a criação de novos impostos, cortes nos gastos com o serviço público e restrições às importações, entre outras (HERBST; SOLUDO, 2001). Nesse contexto, a Nigéria conheceu, ao longo desse ano, um período de enfraquecimento em seu posicionamento ativista. O país estabeleceu relações com o Irã do Xá Mohammad Reza Pahlavi e contraiu grande quantidade de empréstimos de mercados financeiros ocidentais. Além disso, foram realizadas visitas diplomáticas mútuas entre Obasanjo e o presidente dos EUA, Jimmy Carter, e a Nigéria chegou mesmo a demonstrar

3 O preço do barril passou de US\$13,92 (equivalente a US\$52,70, em 2011) para US\$14,02 (equivalente a US\$ 49,37, em 2011) (BP, 2013). 
um apoio inicial às propostas de paz anglo-americanas para o Zimbábue-Rodésia (GAMBARI, 2008). O posicionamento ativista, contudo, foi retomado em finais de 1978, com a nacionalização do banco britânico Barclays, sob a justificativa de que este realizava operações financeiras na África do Sul apartheidista (ABEGUNRIN, 2003).

No ano seguinte, na esteira da Revolução Iraniana, houve um novo aumento significativo nos preços internacionais do petróleo, ${ }^{4}$ proporcionando um novo aumento na arrecadação nigeriana. Nesse contexto, a Nigéria retomou com mais força ainda as políticas ativistas anteriores, encerrando o apoio às propostas de paz anglo-americanas para o Zimbábue-Rodésia, ampliando o apoio financeiro e diplomático à Frente Patriótica de Libertação do país e rejeitando os resultados das suas eleições, que transformavam o bispo Abdel Muzorewa em seu primeiro-ministro.

Ademais, Obasanjo realizou a nacionalização da companhia petrolífera inglesa British Petroleum e estabeleceu um corte de 10\% no fornecimento de petróleo da empresa, como forma de pressionar a primeira-ministra britânica, Margaret Thatcher, a remover sanções impostas ao Zimbábue-Rodésia e a rever a sua intenção de reconhecer o regime de Murozewa (GAMBARI, 2008). Ainda que não haja uma confirmação oficial da efetividade da medida nigeriana, o fato é que o posicionamento britânico se alterou e, no mesmo ano, Londres e os zimbabuanos chegaram a um entendimento, assinando os Acordos de Lancaster House e encerrando as lutas. O regime racista teve fim oficialmente no ano seguinte, com a eleição de Robert Mugabe para a presidência do país, então renomeado como Zimbábue (VISENTINI et al, 2012).

Também em 1979, a Nigéria cortou o fornecimento de petróleo ao Chade, como forma de demonstrar seu descontentamento com os líderes de facções chadianas que travavam uma guerra civil (para a qual a Nigéria enviou forças de paz), retomando o fornecimento apenas em 1982. Gana também foi alvo de um corte no

4 O preço do barril passou de US\$ 14,02, em 1978 (equivalente a US\$ 49,37, em 2011), para US\$31,61, em 1979 (equivalente a US\$99,97, em 2011), cerca de $100 \%$ de aumento (BP, 2013). 
fornecimento de petróleo nigeriano no final da década de 1970, em represália ao golpe que levou Jerry Rawling ao poder (ADEBAJO, 2008). O fim da década de 1970 foi marcado pela redemocratização da Nigéria, que deixou de ser um regime militar e elegeu um presidente civil, Alhaji Shehu Shagari, que deu início à Segunda República (OLIVEIRA, 2012).

A década que se seguiu foi marcada por um declínio na importância internacional da Nigéria. A má gestão econômica do governo Shagari, entre 1979 e 1983, levou a uma crise de endividamento que, à medida que se aprofundava, tornava cada vez mais difícil ao país opor-se diretamente às potências ocidentais no cenário internacional. A dívida internacional do país, que em 1980 era de US\$ 3,4 bilhões, passou para US\$17,3 em 1985 e US\$ 32,9 bilhões em 1990 (OGBE, 1992). Além disso, o fim do boom do petróleo, com a redução da produção, associado à queda do preço internacional a partir de 1980, impôs sérias limitações à ferramenta mais importante da política externa nigeriana na década de 1970.

Em 1981, os preços internacionais do petróleo conheceram uma queda, ${ }^{5}$ devido, sobretudo, a uma recessão econômica internacional e à descoberta de novas reservas do produto em países que não eram membros da OPEP (BARROS; GIL-ALANA; PAYNE, 2011), arrastando a Nigéria para uma recessão que duraria até o início da década de 1990. Entretanto, não houve uma reestruturação da economia nigeriana, optando-se por recorrer a empréstimos internacionais. Em 1982, a Nigéria recebeu 1,5 bilhões de nairas $^{6}$ (pouco mais de US\$ 1 bilhão) em ajuda externa do Fundo Monetário Internacional (FMI), e 400 milhões de nairas (aproximadamente US\$ 269 milhões) em empréstimo da Arábia Saudita (FALOLA; HEATON, 2008). Os empréstimos obtidos pelo governo não impediram a decadência econômica do país, que teve uma queda de $85 \%$ em suas reservas externas e uma duplicação de sua dívida externa entre 1980 e 1983. Além disso, a produção de

5 Passando de US\$36,83 (equivalente a US\$102,62, em 2011) para US\$35,93 (equivalente a US\$90,75, em 2011) por barril (BP, 2013).

6 A naira foi adotada em 1973, e passou a substituir a Libra nigeriana, que era usada até então. 
petróleo decaiu no período, passando de 2 milhões de barris por dia em 1980 para 1,3 milhões de barris por dia em 1983, com uma diminuição de mais de $8 \%$ do PIB e um aumento de até 50\% da inflação (FALOLA; HEATON, 2008). A grande instabilidade e insatisfação interna com o governo Shagari abreviaram a duração da Segunda República, e um novo golpe militar foi realizado em dezembro de 1983, levando o General Buhari ao poder

\section{Gráfico 1 - Produção petrolífera nigeriana, em milhares de barris (1965-1990)}

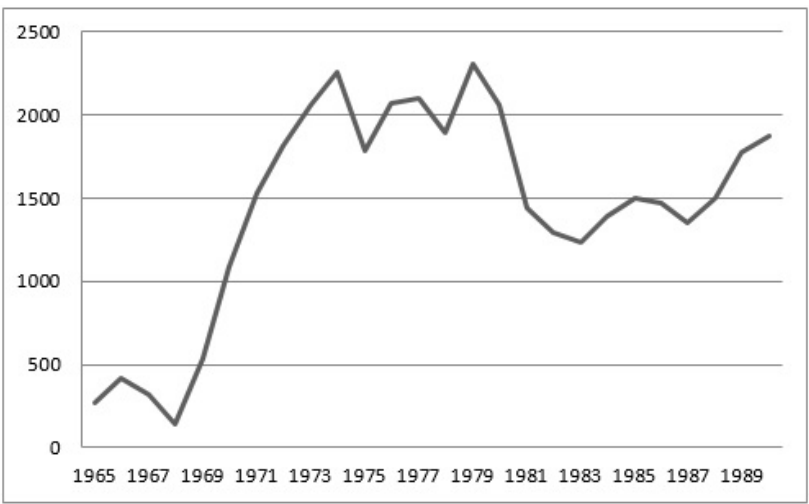

Fonte: British Petroleum (2013), elaboração nossa.

Durante o governo Buhari, a situação econômica da Nigéria continuou se deteriorando e as medidas de austeridade adotadas pelo governo não tiveram sucesso em reestruturar (ou ao menos impedir uma degradação maior) a economia nigeriana. O preço internacional do petróleo, que havia atingido a marca de US\$ 36,83 (o equivalente a US\$ 102,62, em 2011) por barril em 1980, sofreu sucessivas quedas nos anos que se seguiram, chegando a US\$ 28,78 (o equivalente a US\$ 63,60 em 2011) em 1984 e US\$ 27,56 (o equivalente a US\$ 58,81, em 2011) em 1985, implicando em uma grande queda na arrecadação do governo federal. Somouse a isso a dificuldade do governo em renegociar o pagamento da dívida externa nigeriana, que à época consumia quase 40\% da arrecadação federal, com o FMI. Para aceitar uma renegociação nos prazos de pagamento da dívida, o FMI impunha à Nigéria a 
adoção de um Programa de Ajuste Estrutural (PAE), que consistia em uma série de reformas que visavam a estabilizar economias fragilizadas, através da redução de tarifas e de gastos do governo, da privatização de empresas operadas pelo Estado e de propriedade estatal, do fim de subsídios e de controle de preços e da desvalorização monetária. Buhari, entretanto, não aceitou os termos impostos, não obtendo uma expansão no prazo de pagamento da dívida (AKINTERINWA, 2001).

Frente à menor disponibilidade de recursos vivenciada pelo país, foi elaborado pelo Ministério das Relações Exteriores nigeriano, em 1984, um policy paper, que reestruturou os conceitos e abordagens da política externa do país. O documento definia que a política externa nigeriana deveria seguir o princípio de círculos concêntricos, que estabeleceriam prioridades e posicionamentos do país nos diferentes âmbitos da política internacional, possibilitando a adoção de políticas mais assertivas e que demandassem menos recursos materiais e financeiros (GAMBARI, 2008). Apoiada nesse novo princípio orientador de sua política externa, a Nigéria retomou um papel ativo no cenário internacional. Na questão do Saara Ocidental, o país teve papel destacado, reconhecendo a República Árabe Saaráui Democrática. Além disso, o país teve sucesso em retomar seu status de país da Linha de Frente, apoiando a luta pela independência da Namíbia e o fim do apartheid na África do Sul, além de realizar novo boicote aos jogos Olímpicos, em 1984 (WRIGHT; OKOLO, 1999). Em agosto de 1985, Buhari sofreu um golpe, sendo deposto e substituído pelo Major General Ibrahim Badamas Babangida.

Contrariamente a seu antecessor, Babangida promoveu, em 1986, a adoção de um Programa de Ajuste Estrutural, que permitiu o reescalonamento da dívida para a década de 1990, além de viabilizar novas linhas de crédito (METZ, 2002). O PAE possuía diversos objetivos: alcançar o equilíbrio fiscal e garantir a viabilidade da balança de pagamentos através da reestruturação dos padrões de consumo e produção da economia; eliminar as distorções de preços; reduzir a ampla dependência da exportação de petróleo e da importação de bens de consumo; aprimorar a base 
econômica da economia de consumo local; e promover o crescimento sustentável (ADEJUMOBI, 1995).

Diversas medidas foram adotadas nesse contexto. O governo promoveu uma taxa de câmbio flutuante (com a qual pretendia diminuir a demanda por moeda estrangeira, diminuindo assim a pressão sobre o balanço de pagamentos - mas que teve como resultado imediato uma desvalorização de 400\% da naira), a desregulação das taxas de juros (a partir de 1987), a redução (de 74 para 16) no número de produtos com a importação restringida e a introdução de uma nova política industrial, que invalidava dois decretos de 1972 e $1977^{7}$ e, assim, permitia a participação de estrangeiros em todas as áreas da economia. Além disso, foram estabelecidos controles rígidos para desencorajar a contração de novos empréstimos externos pelos diversos órgãos e agências do governo, em uma tentativa de melhor gerenciar a dívida externa do país (ADEJUMOBI, 1985).

O Programa de Ajuste Estrutural teve efeitos imediatos no país. Por um lado, ele logrou reduzir os gastos do governo com o serviço da dívida e, através da desvalorização da naira, associada à redução de tarifas, contribuiu para um relativo aumento na produção agrícola e de matérias-primas, o que promoveu uma melhora na condição de vida das populações das áreas rurais. Por outro, os níveis de desemprego subiram e diversas empresas, como consequência do aumento dos impostos, passaram a operar abaixo da capacidade, tendo sua margem de lucro reduzida, devido à alta no custo de importação de matérias-primas, gerando uma diminuição nos salários, ou mesmo a demissão de funcionários.

A desvalorização da moeda contribuiu significativamente para o aumento da inflação, cuja taxa, entre 1988 e 1995, ficou entre $40 \%$ e $70 \%$. O fim dos subsídios governamentais também teve grande impacto na economia nigeriana, elevando o preço dos combustíveis em cerca de 1000\%, entre 1988 e 1993. Além disso, a redução dos gastos governamentais implicou na diminuição dos serviços públicos, que já eram escassos (FALOLA; HEATON, 2008).

7 Esses decretos restringiam a realização de diversas atividades econômicas apenas a nigerianos (MOHAMMED, 1985) 
Para cumprir com os demais pontos do PAE, Babangida anunciou um amplo plano de privatizações em 1988, que incluía mais de cem empresas estatais nos mais diversos setores. Dois anos após o anúncio do plano, contudo, apenas quinze empresas haviam sido vendidas, refletindo a dificuldade em atrair investimentos estrangeiros para o país. Associado a isso, a tentativa de aproximar-se do mundo islâmico, com a adesão à Organização da Conferência Islâmica, em 1986, contribui para diminuir a estabilidade interna da Nigéria, fomentando disputas entre grupos cristãos e muçulmanos, deteriorando ainda mais a sua capacidade de projeção internacional (FALOLA; HEATON, 2008).

Em termos de política externa, o governo Babangida mostrou-se menos efetivo do que os governos anteriores, o que é atribuído, sobretudo, a uma diminuição significativa da capacidade econômica nigeriana, causada especialmente pela queda no preço internacional do petróleo (WRIGHT; OKOLO, 1999). Apesar disso, em 1990, o país se mostrou capaz de promover, no contexto da ECOWAS, a criação do Grupo de Monitoramento da ECOWAS (Economic Community of West African States Monitoring Group - ECOMOG), responsável pela intervenção, liderada também pela Nigéria, nas guerras civis da Libéria e de Serra Leoa, em 1991 (RÖNNBÄCK, 2008).

\section{CONCLUSÃO}

Em um período inicial, ao longo da Primeira República, a Nigéria apresentou uma política externa hesitante, alinhada às potências e interesses ocidentais. Contudo, a partir do início da década de 1970, o país logrou adotar um posicionamento mais autônomo e ativo, assumindo papel destacado não só em sua região, mas no continente africano como um todo. Os períodos de maior autonomia e assertividade da política externa nigeriana, portanto, parecem estar diretamente ligados às fases em que a combinação entre os preços internacionais do petróleo e o volume da produção da commodity no país encheu os cofres públicos. Nesse contexto, nos choques do petróleo, em 1973 e em 1979, quando o preço 
internacional da commodity conheceu um aumento substancial, foram de suma importância para alavancar a autonomia nigeriana.

Nesse sentido, Khadiagala e Lyons (2001) salientam que o destacado desempenho econômico nigeriano foi fundamental para que o país conseguisse adotar um papel de liderança regional ao longo da década de 1970 e promover a criação da ECOWAS em 1975. Adebajo (2008), por sua vez, ressalta a importância da assistência econômica fornecida pela Nigéria aos vizinhos mais pobres como uma das ferramentas essenciais para a liderança nigeriana e para a consecução da criação da comunidade. Em grande medida, as visões desses autores se alinham aos argumentos de Veseth (2001), relativo à importância do comércio internacional para a EPI, e de Ravenhill (2008), que destaca a importância da capacidade de um ator de estabelecer e promover agendas específicas, através de interações econômicas, de forma a promover os seus interesses. Nesse sentido, não fosse a capacidade econômica nigeriana do período, condicionada, sobretudo, pelos lucros oriundos do petróleo, possivelmente o país não tivesse sido capaz de promover a criação da comunidade.

Ao longo da década de 1970, o país adotou uma postura de não-alinhamento, e, ao mesmo tempo, aproximou-se, ainda que de forma bastante discreta, da URSS (que fora responsável por grande parte do fornecimento de armamentos para o governo federal nigeriano à época da guerra civil do país, em detrimento das potências ocidentais), mas manteve os laços com os países ocidentais (NAFZIGER, 1992). Além disso, o país se tornou uma liderança africana na luta anticolonialista e anti-apartheid, apoiando diversos movimentos em todo o continente. Nesse sentido, a nacionalização do Barclay's e da British Petroleum como forma de pressionar o governo britânico a alterar seu posicionamento nessas questões se mostrou efetiva.

A partir de 1980, as constantes quedas no preço do petróleo e a produção inferior à da década anterior prejudicaram significativamente a arrecadação nigeriana. A má gestão econômica dos governos que se seguiram levou a uma crise de endividamento que, à medida que se aprofundou, tornou cada vez mais difícil ao país opor-se diretamente às potências ocidentais no cenário 
internacional. Ainda que tenha tido algumas realizações importantes no período, como as tentativas de estabilização da região, e a criação da ECOMOG, em linhas gerais a autonomia da política externa nigeriana se viu reduzida no período, sobretudo em relação aos anos 1970. A contração de diversos empréstimos e a adoção do Programa de Ajuste Estrutural, em 1986, são bastante representativas dessa mudança. A década de 1980 foi, portanto, marcada pelo declínio na importância internacional da Nigéria, associado diretamente à diminuição da arrecadação oriunda do petróleo.

\section{REFERÊNCIAS}

ABEGURIN, O. Nigerian Foreign Policy under Military Rule, 1966-1999. Westport Praeger Publishers, 2003.

ADEBAJO, A. Hegemony on a shoestring: Nigeria's post-Cold War Foreign Policy. In: ADEBAJO, A.; MUSTAPHA, A. R. (Orgs.). Gulliver's Troubles: Nigeria's Foreign Policy after the Cold War. South Africa: University of KwaZulu-Natal Press, 2008. Cap. 1, p. 1-37.

ADEJUMOBI, S. Adjustment Reform and Its Impact on the Economy and Society. In: ADEJUMOBI, S.; MOMOH, A. (Eds.). The Political Economy of Nigeria Under Military Rule: 1984-1993. Harare: Sapes, 1995, cap. 9, p. 163-194.

AKINTERINWA, B. A. Nigeria In the World: Issues and Problems for the Sleeping Giant. Lagos: Pumark Educational Publishers, 2001.

\section{AZUBUIKE, L. O. Privatization and Foreign Investments in} Nigeria. Boca Raton: Brown Walker, 2009.

BARROS, C. P.; GIL-ALANA, L. A.; PAYNE, J. E. An analysis of oil production by OPEC countries: Persistence, breaks and outliers. Energy Policy. Philadelphia, v. 39, n.1, p. 442-453, 2011.

BRITISH PETROLEUM (BP). Statistical Review 2013 Workbook. 2013. Disponível em: <http://www.bp.com/content/dam/ bp/excel/Statistical-Review/statistical_review_of_world_ energy_2013_workbook.xlsx>. Acesso em: 15 abr. 2014.

FALOLA, T.; HEATON, M. M. A History of Nigeria. London: 
Cambridge University Press, 2008.

FRANCIS, D. J. Uniting Africa: Building Regional Peace and Security Systems. Hampshire: Ashgate Publishing Limited, 2006.

FRYNAS, J. G.; PAULO, M. A new scramble for African oil? Historical, political and business perspectives. African Affairs, Oxford, V. 106, n. 423, p. 229-251, 2007.

GAMBARI, I. A. From Balewa to Obasanjo: The theory and practice of Nigeria's foreign policy. In: ADEBAJO, A.; MUSTAPHA, A. R. (Orgs.). Gulliver's Troubles: Nigeria's Foreign Policy after the Cold War. South Africa: University of KwaZulu-Natal Press, 2008, cap. 3, p. 58-80.

HERBST, J.; SOLUDO, C. C. Nigeria. In: DEVARAJAN, S.; DOLLAR, D. R.; HOLMGREN, T. (Eds.). Aid \& Reform in Africa. Washington: World Bank Publications, 2001, cap. 11, p. 645-678.

KHADIAGALA, G. M.; LYONS, T. Foreign Policy Making in Africa: An Introduction. In: KHADIAGALA, G. M.; LYONS, T. African foreign policies: Power and Process. Colorado: Lynne Rienner Publishers, 2001.

MACHADO, I. B. L. O Brasil na África: uma análise das relações Brasil-Nigéria entre 1961 e 2012. 2013. Trabalho de Conclusão de Curso. Universidade Federal do Rio Grande do Sul, Faculdade de Ciências Econômicas, Porto Alegre, 94p.

MOHAMMED, I. The Nigerian Enterprises Promotion Decrees (1972 and 1977) and Indigenisation in Nigeria. 1985. Tese (Doutorado). University of Warwick, Department of Politics, Coventry, 407p. Disponível em: <http://wrap.warwick. ac.uk/34591/1/WRAP_THESIS_Mohammed_1985.pdf.> Acesso em: 20 mar. 2014.

NAFZIGER, E. W. The Economy. In: METZ, H. C. Nigeria: a country study. Washington: Library of Congress, 1992. Cap. 3, p.158-202.

NUGENT, P. Africa since independence: a comparative history. New York: Palgrave, 2004.

OGBE, N. E. Evaluation of Nigeria's Debt Relief Experience (1985-1990). Research Programme on Financial Policies for the global dissemination of Economic Growth. OECD DEVELOPMENT 
CENTRE, Working Paper No. 55, 1992, 38p.

OHUOCHA, C. Nigeria surpasses South Africa as continent's biggest economy. Reuters, 2014. Disponível em: <http://uk.reuters.com/ article/2014/04/06/uk-nigeria-gdp-idUKBREA350CG20140406>. Acesso em: 15 abr. 2014.

OLIVEIRA, G. Z. Nigéria: história da política externa e das relações internacionais. 2012. Trabalho de Conclusão de Curso. Universidade Federal do Rio Grande do Sul, Faculdade de Ciências Econômicas, Porto Alegre, 113p.

RAVENHILL, J. The Study of Global Political Economy. In: RAVENHILL, J. Global Political Economy. Oxford: Oxford University Press, 2008, cap. 1, p. 3-28.

RÖNNBÄCK, A-S. ECOWAS and West Africa's Future - Problems or Possibilities? Umeå Working Papers in Political Science, Umeå, n. 3, p. 1-33, 2008.

VESETH, M. What is International Political Economy? 2001. Disponível em: <www2.ups.edu/ipe/whatis.pdf>. Acesso em 15 abr. 2014.

VISENTINI, P. F. A África e as Potências Emergentes: nova partilha ou cooperação Sul-Sul? Porto Alegre: Leitura XXI/ CEBRAFRICA, 2013.

VISENTINI, P. F. et al. Os países africanos: Diversidade de um continente. Porto Alegre: Leitura XXI/CEBRAFRICA, 2012.

WILSON III, E. J. Energy, Africa and world politics. The Review of Black Political Economy. New York, v. 3, n. 4, p. 27-41, 1973.

WRIGHT, S.; OKOLO, J. E. Nigeria: Aspirations of Regional Power. In: WRIGHT, S. (Ed.). African foreign policies. Boulder: Westview Press, 1999, cap. 7, p. 118-132. 